\title{
The Pathophysiology of Colonic Diverticulosis: Inflammation versus Constipation?
}

\author{
Walter Elisei $^{\mathrm{a}}$ Antonio Tursi ${ }^{\mathrm{b}}$

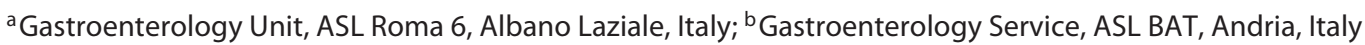

\section{Keywords}

Constipation · Diverticulosis · Inflammation ·

Pathophysiology

\begin{abstract}
Background: Diverticulosis of the colon is the most common anatomic alteration of the human colon, but the pathophysiologic mechanisms of its occurrence are not completely understood. Summary: Constipation has been considered the key factor for diverticulosis occurrence. However, several fine papers questioned this pathogenetic hypothesis, showing on the contrary an inverse relationship between low number of bowel movements and diverticulosis occurrence. In the last years, several papers have showed the role of lowgrade inflammation in the occurrence of symptoms in people having diverticulosis, as well as its role on symptom persistence following acute diverticulitis, even if the evidence available is not so strong. Although the trigger of this lowgrade inflammation is currently under debate, some preliminary evidence found colonic dysbiosis linked to symptom occurrence in those patients. Key Messages: Constipation no longer seems the leading cause for diverticulosis occurrence, while low-grade inflammation could play a role in symptom occurrence.

(c) 2018 S. Karger AG, Basel
\end{abstract}

\section{Introduction}

The incidence of diverticulosis and diverticular disease of the colon is increasing worldwide and is becoming a significant burden on national health systems in terms of direct and indirect costs. Diverticulosis is commonly found in developed countries, slightly more frequently in the USA than in Europe, and is a rare condition in Africa. However, some indication is available that the prevalence of colonic diverticulosis is increasing throughout the world, probably because of changes in lifestyle [1]. Although advancing age is obviously associated with diverticulosis, this association is not strong per se, as it is not age but the prolonged time course during which the colonic wall is exposed and making the colon more susceptible to other pathogenetic factors.

European countries with a lower socioeconomic status report a $5.3 \%$ frequency of diverticulosis in patients aged $30-39,8.7 \%$ in those aged $40-49,19.4 \%$ between 50 and 59 , and up to $29.6 \%$ in subjects over the seventh decade, while maximal incidences were found in patients aged 70-79 and above 80 of 40.2 and 57.9\%, respectively [2].

Although most people with colonic diverticulosis remain asymptomatic, about $20 \%$ will develop symptoms without complications, experiencing the so-called symp-

\section{KARGER}

(c) 2018 S. Karger AG, Basel

E-Mail karger@karger.com

www.karger.com/iid
Antonio Tursi, MD

Gastroenterology Service, ASL BAT

Via Torino, 49

IT-76123 Andria (Italy)

E-Mail antotursi@tiscali.it 
tomatic uncomplicated diverticular disease (SUDD), of whom $15 \%$ will ultimately develop diverticulitis, with or without complications [3]. Despite the significant burden of the disease, the pathogenesis is poorly understood and several etiological factors may play a role in its onset.

\section{Terminology}

Diverticulosis is merely the presence of colonic diverticula; these may, or may not, become symptomatic or complicated. Diverticular disease is defined as clinically significant and symptomatic diverticulosis; this may be from true diverticulitis or from other less well-understood manifestations (e.g., visceral hypersensitivity in the absence of verifiable inflammation). The overarching term "diverticular disease" implies that the anatomical lesion (diverticulosis) rises to the level of an illness. SUDD is a subtype of diverticular disease in which there are persistent abdominal symptoms attributed to diverticula in the absence of macroscopically overt colitis or diverticulitis. This definition is generally shared in Europe but not in other countries, such as the United States.

Diverticulitis is the macroscopic inflammation of diverticula with related acute or chronic complications. Diverticulitis can be uncomplicated or complicated. It is uncomplicated when computerized tomography (CT) shows colonic wall thickening with fat stranding, while it is complicated when CT finds complicating features of abscess, peritonitis, obstruction, fistulas, or hemorrhage.

\section{Pathophysiologic Mechanisms of Diverticulosis Occurrence}

Diverticulosis is characterized by the presence of saclike protrusions (diverticula) which form when colonic mucosa and submucosa herniated through defects in the muscle layer of the colon wall [3]. Diverticula are thought to develop from age-related degeneration of the mucosal wall and segmental increases in colonic pressure resulting in bulging at points of weakness, typically at the insertion of the vasa recta.

The underlying pathological mechanisms that cause the formation of colonic diverticula remain unclear. These are likely to be the result of complex interactions between age, diet, colonic microbiota, genetic factors, colonic motility, and changes in colonic structure. In this paper, we focused on the roles of inflammation and colonic motility as part of the physiopathology of diverticulosis.

\section{Inflammation}

As stated, diverticulosis is merely the presence of colonic diverticula without symptoms or macroscopic/microscopic signs of inflammation. In this way, no signs of inflammation should be detected, both at endoscopic and also at histological assessment. Two European papers, published at the beginning of this decade, found that no signs of histological inflammation were found in people having colonic diverticulosis $[4,5]$. These data have been recently confirmed by a study conducted in the United Stated. Peery et al. [6] analyzed data about colonic mucosal biopsy specimens from people having diverticulosis. Assessing levels of interleukin (IL) 6 (IL6), IL10, tumor necrosis factor (TNF), and numbers of immune cells (CD4+, CD8+, CD27+, and mast cell tryptase), they found that there was no association between diverticulosis and TNF (odds ratio [OR], 0.85; 95\% confidence interval [CI], 0.63-1.16) and no association with CD4+ cells (OR, 1.18; 95\% CI, 0.87-1.60), CD8+ cells (OR, 0.97; 95\% CI, 0.71-1.32), or CD 57+ cells (OR, 0.80 ; 95\% CI, 0.591.09). Compared with controls without diverticulosis, biopsy specimens from people having diverticulosis were less likely to express the inflammatory cytokine IL6 (OR, 0.59 ; 95\% CI, 0.36-0.96). Moreover, there was no association between diverticulosis and irritable bowel syndrome (IBS) (OR, 0.53; 95\% CI, 0.26-1.05) [6]. Diverticulosis therefore does not show inflammation.

A different scenario may be observed when we analyze patients with SUDD. Unfortunately, there is still no consensus about this form of the disease; this because SUDD is characterized by nonspecific attacks of abdominal pain without macroscopic evidence of an inflammatory process, with abdominal pain, bloating, and changes in bowel habits that may resemble IBS. As a consequence, several authors still talk about "IBS with diverticulosis." For example, Jung et al. [7] found that IBS occurs 4.7-fold more likely in patients after an episode of acute diverticulitis than controls and, more recently, Järbrink-Sehgal et al. [8] found that diverticulosis was associated with diarrhea-predominant IBS (OR, 9.55; 95\% CI, 1.08-84.08; $p=0.04)$.

It is likely that those patients are suffering from SUDD than from "IBS with diverticulosis," even when we describe symptom occurrence/persistence following an episode of acute diverticulitis. This is because IBS and SUDD are not the same clinical entity, as showed by clinical data currently available. IBS and SUDD do not share the same epidemiology $[7,9]$ but only part of clinical features, and patients with SUDD do not generally fulfill IBS criteria $[10,11]$. Moreover, the characteristics of the abdominal 
pain (left lower-abdominal pain lasting for more than 24 $\mathrm{h}$ characterizes SUDD, diffuse and short-lived abdominal pain characterizes IBS) is likely the most effective clinical tool in discriminating between patients with SUDD and those having IBS $[10,11]$. Finally, persistence of symptoms following an episode of acute diverticulitis has been linked to several factors, ranging from significant attenuation in serotonin-transporter expression to persistence of low-grade inflammation [12-14]. These findings have been recently confirmed by Lahat et al. [15], who found TNF $\alpha$, IL6 and IL1 $\beta$ to be significantly higher in patients having symptom persistence following severe uncomplicated acute diverticulitis.

Several additional pieces of evidence reinforce the hypothesis that low-grade inflammation may play a significant role in determining symptom occurrence and complication in those patients: fecal calprotectin is increased in SUDD versus people having diverticulosis or healthy controls [16, 17]; SUDD shows a significant microscopic inflammatory infiltrate $[18,19]$. This microscopic inflammation, ranging from increased chronic lymphocytic infiltrate to active neutrophilic infiltrate, seems to be linked to the severity of the disease [4]; SUDD shows an enhanced expression of pro-inflammatory cytokines as TNFa $[5,20,21]$, which decreases parallel to response to therapy $[22,23]$.

Inducible nitric oxide synthase (iNOS) expression was significantly increased in SUDD and SUDD following acute diverticulitis (SUDD+AD) patients compared to controls $(+2.04-$ and +2.86 -fold increase vs. controls, respectively; $p<0.05)$. Finally, basal NO expression was significantly increased in SUDD+AD compared to controls [24].

Based on the current data, and awaiting stronger evidence, we suggest that SUDD could be considered as a separate clinical entity distinct from IBS, even if some studies still define patients with SUDD as people having "symptomatic diverticulosis."

Why inflammation occurs is still under debate. It has been hypothesized that dysbiosis may be the trigger of symptoms in people having diverticulosis [25]. A recent, retrospective study found that chronically recurrent diverticulitis has a specific microbial ecosystem that differs from that of uninflamed colonic tissue [26]. Moreover, two recent pilot studies found that SUDD patients have dysbiosis when compared with patients with simple diverticulosis, and this dysbiosis seems to influence also the host metabolome $[27,28]$. No further information can be drawn from these preliminary studies due to the small number of patients involved, and further studies are needed to elucidate the exact mechanisms that lead from dysbiosis to inflammation.

Not only may intestinal inflammation have a role in the occurrence of SUDD, but also pro-inflammatory conditions outside the intestine may explain the occurrence of diverticular disease complications. For example, obesity is a risk factor for acute diverticulitis and its complications [29-31], and we know today that this risk is linked to the pro-inflammatory effect of adipokines and chemokines released by adipose tissue [31].

Persistent low-grade inflammation of the colon may explain clinical symptom persistence following acute diverticulitis, even if surgically treated. In fact, we know that up to $20 \%$ of patients complain of persistent abdominal pain after surgical treatment of diverticulitis [32], and the quality of life of those patients is significantly worse [33]. It has been hypothesized that persistent symptoms are linked to increased pro-inflammatory cytokines with persistent chronic inflammation in mucosal biopsy samples, as recently confirmed by Lahat et al. [15].

Table 1 summarizes data from the main studies assessing the role of inflammation in diverticular disease occurrence.

\section{Constipation}

Over 40 years ago, Painter and Burkitt [34] put forth their hypothesis that a "low-residual diet," one that was high in processed sugars and low in fiber, was responsible for the development of colonic diverticula due to increased occurrence of constipation. This hypothesis was based mainly on observational data, but the detection of disturbances in the normal neural content of vasoactive intestinal polypeptide in the bowel wall in both idiopathic constipation and diverticular disease seemed to support this hypothesis [35]. However, three recent studies questioned the association constipation/diverticulosis. In the first study, conducted in the United States, Peery et al. [36] studied 2,014 subjects who underwent a screening colonoscopy for colorectal cancer and then assessed their dietary intake and bowel movements by questionnaire. A total of 878 patients $(41 \%)$ were noted to have diverticulosis on their colonoscopy report. Contrary to long-held belief, the authors found that increased fiber consumption increased the risk of diverticulosis in a dose-dependent fashion. After adjusting for other variables such as age, race, and body mass index, individuals in the highest quartile of total fiber intake had an increased diverticulosis prevalence ratio (1.30; 95\% CI, 1.13-1.50) compared to the lowest quartile. In addition, frequent bowel movements were positively associated with diverticulosis [36]. 
Table 1. Pathophysiologic mechanism of diverticulosis occurrence: inflammation

\begin{tabular}{|c|c|c|c|}
\hline Study [Ref.] & Clinical setting & Methods & Results \\
\hline Peery et al. [6] & Diverticulosis & $\begin{array}{l}\text { Colonic } \\
\text { mucosal } \\
\text { biopsy }\end{array}$ & $\begin{array}{l}\text { No association between diverticulosis and tumor necrosis factor (OR, } 0.85 \text {; } \\
95 \% \text { CI, 0.63-1.16), and no association with CD4+ cells (OR, 1.18; } 95 \% \mathrm{CI} \text {, } \\
0.87-1.60), \mathrm{CD} 8+\text { cells (OR, 0.97; 95\% CI, 0.71-1.32), or CD } 57+\text { cells (OR, } \\
0.80 ; 95 \% \mathrm{CI}, 0.59-1.09) \text {. } \\
\text { Compared with controls without diverticulosis, biopsy specimens from } \\
\text { individuals with diverticulosis were less likely to express the inflammatory } \\
\text { cytokine IL6 (OR, 0.59; 95\% CI, 0.36-0.96). } \\
\text { No association between diverticulosis and irritable bowel syndrome (OR, } \\
0.53 ; 95 \% \text { CI, } 0.26-1.05) \text {. }\end{array}$ \\
\hline $\begin{array}{l}\text { Narayan et al. [18] } \\
\text { Tursi et al. [19] }\end{array}$ & SUDD & $\begin{array}{l}\text { Colonic } \\
\text { mucosal } \\
\text { biopsy }\end{array}$ & $\begin{array}{l}\text { Diverticular disease shows a significant microscopic inflammatory infiltrate, } \\
\text { ranging from increased chronic lymphocytic infiltration to active neutro- } \\
\text { philic infiltrate related to the severity of the disease. }\end{array}$ \\
\hline Turco et al. [24] & SUDD & $\begin{array}{l}\text { Colonic } \\
\text { mucosal } \\
\text { biopsy }\end{array}$ & $\begin{array}{l}\text { iNOS expression was significantly increased in SUDD and SUDD with pre- } \\
\text { vious acute diverticulitis (SUDD+AD) patients compared to controls } \\
(+2.04-\text { and }+2.86 \text {-fold increase vs. controls, respectively; } p<0.05) \text {; basal } \\
\text { NO expression was significantly increased in SUDD+AD compared to con- } \\
\text { trols. }\end{array}$ \\
\hline
\end{tabular}

OR, odds ratio; CI, confidence interval; SUDD, symptomatic uncomplicated diverticular disease; TNF, tumor necrosis factor; iNOS, inducible nitric oxide synthase; $\mathrm{NO}$, nitric oxide.

In the second study, conducted in Japan, Yamada et al. [37] studied 1,066 subjects who underwent colonoscopy analyzing bowel habits and stool form. After adjusting for age and sex, the presence of constipation was associated with a significantly reduced likelihood of diverticula (OR, $0.70 ; 95 \%$ CI, 0.52-0.93). When assessed according to the location of diverticula, the presence of constipation was associated with a significantly decreased likelihood of left-sided (OR, 0.39; 95\% CI, 0.16-0.93), but not rightsided (OR, 1.10; 95\% CI, 0.48-2.53), diverticula. Furthermore, stool form was unrelated to the presence or absence of diverticula [37]. The last study, conducted in Austria by Braunschmid et al. [38], studied 976 patients who participated in the nationwide colorectal cancer screening program in four medical centers between 2008 and 2009, and in whom colonic diverticular disease was found in 290 participants (30\%). Using the constipation scoring system by Agachan et al. [39], the authors found that the median constipation score in patients with diverticular disease was 3 (range $0-18$ ), comparable to patients without diverticula (median 3, range $0-20)(p=0.1073)$ [38].

Although patient selection may be questionable (it is often unclear whether those studies enrolled people hav- ing diverticulosis or suffering from symptomatic diverticular disease), these studies challenge the concept that low fiber diet and constipation contribute to the development of diverticulosis and open the door to new pathophysiologic concepts. Neural degeneration with age may also contribute to diverticulosis occurrence, since several studies suggest reduction in neurons in the myenteric plexus [40] and decreased myenteric glial cells and interstitial cells of Cajal [41] in those people. Denervation hypersensitivity has also been reported [42], and these abnormalities of enteric nerves might lead to uncoordinated contractions and high pressure, leading to diverticulosis occurrence. The associated muscular hypertrophy and altered enteric nerves [43] may also result from remodeling colonic architecture after acute inflammation, since numerous animal studies have found these findings associated with muscular hypertrophy, abnormal motility [44], visceral hypersensitivity, and altered neurochemical coding $[45,46]$. Such changes may account for the common development of recurrent abdominal pain and disturbed bowel habits following acute diverticulitis [47] and the finding of visceral hypersensitivity in patients with symptomatic diverticular disease $[5,48]$. 
Table 2. Pathophysiologic mechanism of diverticulosis occurrence: constipation

\begin{tabular}{|c|c|c|c|}
\hline Study [Ref.] & Clinical setting & Methods & Results \\
\hline Painter and Burkitt [34] & Diverticulosis & $\begin{array}{l}\text { Observational } \\
\text { data }\end{array}$ & $\begin{array}{l}\text { A "low-residual diet," one that was high in processed sugars and } \\
\text { low in fiber, was responsible for the development of colonic } \\
\text { diverticula due to increased constipation. }\end{array}$ \\
\hline Peery et al. [36] & Diverticulosis & $\begin{array}{l}\text { Observational } \\
\text { data }\end{array}$ & $\begin{array}{l}\text { Increased fiber consumption increased the risk of diverticulosis in } \\
\text { a dose-dependent fashion. After adjusting for other variables such } \\
\text { as age, race, and body mass index, individuals in the highest } \\
\text { quartile of total fiber intake had an increased prevalence ratio } \\
\text { (1.30; } 95 \% \mathrm{CI}, 1.13-1.50) \text { compared to the lowest quartile. } \\
\text { In addition, frequent bowel movements were positively associated } \\
\text { with diverticulosis. }\end{array}$ \\
\hline Yamada et al. [37] & Diverticulosis & $\begin{array}{l}\text { Observational } \\
\text { data }\end{array}$ & $\begin{array}{l}\text { The presence of constipation was associated with a significantly } \\
\text { reduced likelihood of diverticula (OR, 0.70; 95\% CI, 0.52-0.93). }\end{array}$ \\
\hline Braunschmid et al. [38] & Diverticulosis & $\begin{array}{l}\text { Observational } \\
\text { data }\end{array}$ & $\begin{array}{l}\text { The median constipation score in patients with diverticular disease } \\
\text { was } 3 \text { (range } 0-18) \text { and comparable to patients without diverticula } \\
\text { (median 3, range } 0-20)(p=0.1073) \text {. }\end{array}$ \\
\hline
\end{tabular}

Table 2 summarizes data from the main studies assessing the role of constipation in diverticulosis and diverticular disease occurrence.

\section{Summary and Conclusion}

Diverticulosis is a common condition that sometimes becomes symptomatic and may lead to severe complications. Its prevalence is higher in the Western world, but it is increasing in the developing world as well. The pathophysiologic hypothesis behind diverticulosis has changed in the last years. Constipation is no more considered the key driver of diverticulosis, but we have to take into consideration that occurrence of diverticulosis is probably of multifactorial origin, ranging from structural alteration of the colonic wall to microbial dysbiosis. However, most mechanisms leading to its occurrence remain to be elucidated, and the occurrence or persistence of symptoms remains an active area of debate. Some hypotheses have been advanced, ranging from bacterial overgrowth to the presence of low-grade inflammation. However, further studies are needed to help elucidate this common entity.

\section{Disclosure Statement}

The authors declare no conflicts of interest.

\section{References}

1 Weizman AV, Nguyen GC: Diverticular disease: epidemiology and management. Can J Gastroenterol 2011;25:295-302.

2 Tursi A: Diverticulosis today: unfashionable and still under-researched. Therap Adv Gastroenterol 2016;9:213-228.

3 Tursi A, Papa A, Danese S: Review article: the current and evolving treatment of colonic diverticular disease. Aliment Pharmacol Ther 2009;30:532-546.

4 Tursi A, Brandimarte G, Elisei W, Giorgetti GM, Inchingolo CD, Danese S, et al: Assessment and grading of mucosal inflammation in colonic diverticular disease. J Clin Gastroenterol 2008;42:699-703.
5 Humes DJ, Simpson J, Smith J, Sutton P, Zaitun A, Bush D, et al: Visceral hypersensitivity in symptomatic diverticular disease and the role of neuropeptides and low grade inflammation. Neurogastroenterol Motil 2012; 24:318-e163.

6 Peery AF, Keku TO, Addamo C, McCoy AN, Martin CF, Galanko JA, et al: Colonic diverticula are not associated with mucosal inflammation or chronic gastrointestinal symptoms. Clin Gastroenterol Hepatol 2018;16:884-891.
7 Jung HK, Choung RS, Locke GR 3rd, Schleck CD, Zinsmeister AR, Talley NJ: Diarrhea-predominant irritable bowel syndrome is associated with diverticular disease: a populationbased study. Am J Gastroenterol 2010;105: 652-661.

8 Järbrink-Sehgal ME, Andreasson A, Talley NJ, Agréus L, Song JY, Schmidt PT: Symptomatic diverticulosis is characterized by loose stools. Clin Gastroenterol Hepatol 2016; 14:1763-1770. 
9 Jones R, Latinovic R, Charlton J, Gulliford M: Physical and psychological co-morbidity in irritable bowel syndrome: a matched cohort study using the General Practice Research Database. Aliment Pharmacol Ther 2006;24: 879-886.

10 Cuomo R, Barbara G, Andreozzi P, Bassotti G, Casetti T, Grassini M, et al: Symptom patterns can distinguish diverticular disease from irritable bowel syndrome. Eur J Clin Invest 2013;43:1147-1155.

11 Tursi A, Elisei W, Picchio M, Giorgetti GM, Brandimarte G: Moderate to severe and prolonged left lower-abdominal pain is the best symptom characterizing symptomatic uncomplicated diverticular disease of the colon: a comparison with fecal calprotectin in clinical setting. J Clin Gastroenterol 2015;49:218221.

12 Aldoori WH, Giovannucci EL, Rimm EB, Wing AL, Trichopoulos DV, Willett WC: A prospective study of diet and the risk of symptomatic diverticular disease in men. Am J Clin Nutr 1994;60:757-764.

13 Costedio MM, Coates MD, Danielson AB, Buttolph TR 3rd, Blaszyk HJ, Mawe GM, et al: Serotonin signaling in diverticular disease. J Gastrointest Surg 2008;12:1439-1445

14 Tursi A, Elisei W, Giorgetti GM, Inchingolo CD, Nenna R, Picchio M, et al: Detection of endoscopic and histological inflammation after an attack of colonic diverticulitis is associated with higher diverticulitis recurrence. J Gastrointestin Liver Dis 2013;22:13-19.

15 Lahat A, Necula D, Yavzori M, Picard O, Halperin S, Eliakim R, Ben-Horin S: Prolonged recurrent abdominal pain is associated with ongoing underlying mucosal inflammation in patients who had an episode of acute complicated diverticulitis. J Clin Gastroenterol 2018, DOI: 10.1097/MCG.0000000000000980.

16 Pezzilli R, Barassi A, Morselli Labate AM, Finazzi S, Fantini L, Gizzi G, et al: Fecal calprotectin levels in patients with colonic polyposis. Dig Dis Sci 2008;53:47-51.

17 Tursi A, Brandimarte G, Elisei W, Giorgetti GM, Inchingolo CD, Aiello F: Faecal calprotectin in colonic diverticular disease: a casecontrol study. Int J Colorectal Dis 2009;24: 49-55.

18 Narayan R, Floch MH: Microscopic colitis as part of the natural history of diverticular disease. Am J Gastroenterol 2002;97(suppl 1):12.

19 Tursi A, Elisei W, Brandimarte G, Giorgetti GM, Aiello F: Predictive value of serologic markers of degree of histologic damage in acute uncomplicated colonic diverticulitis. J Clin Gastroenterol 2010;44:702-706.

20 Simpson J, Sundler F, Humes DJ, Jenkins D, Scholefield JH, Spiller RC: Post inflammatory damage to the enteric nervous system in diverticular disease and its relationship to symptoms. Neurogastroenterol Motil 2009; 21:847-e58.

21 Tursi A, Elisei W, Brandimarte G, Giorgetti GM, Inchingolo CD, Nenna R, et al: Mucosal tumour necrosis factor-alpha in diverticular disease of the colon is overexpressed with disease severity. Colorectal Dis 2012;14:e258e263.

22 Smith J, Humes D, Garsed K, Lam C, Zaitoun A, Bennett A, et al: Mechanistic randomised control trial of mesalazine in symptomatic diverticular disease. Gut 2012;61:A51-A52.

23 Tursi A, Elisei W, Brandimarte G, Giorgetti GM, Inchingolo CD, Nenna R, et al: Mucosal expression of basic fibroblastic growth factor, Syndecan 1 and tumor necrosis factor-alpha in diverticular disease of the colon: a casecontrol study. Neurogastroenterol Motil 2012;24:836-e396.

24 Turco F, Andreozzi P, Palumbo I, Zito FP Cargiolli M, Fiore W, et al: Bacterial stimuli activate nitric oxide colonic mucosal production in diverticular disease. Protective effects of L. casei $\mathrm{DG}^{\circledR}$ (Lactobacillus paracasei CNCM I-1572). United European Gastroenterol J 2017;5:715-724.

25 Quigley EM: Gut microbiota, inflammation and symptomatic diverticular disease. New insights into an old and neglected disorder. J Gastrointestin Liver Dis 2010;19:127-129.

26 Schieffer KM, Sabey K, Wright JR, Toole DR, Drucker R, Tokarev V, et al: The microbial ecosystem distinguishes chronically diseased tissue from adjacent tissue in the sigmoid colon of chronic, recurrent diverticulitis patients. Sci Rep 2017;7:8467.

27 Tursi A, Mastromarino P, Capobianco D, Elisei W, Miccheli A, Capuani G, et al: Assessment of fecal microbiota and fecal metabolome in symptomatic uncomplicated diverticular disease of the colon. J Clin Gastroenterol 2016;50(suppl 1):S9-S12.

28 Barbara G, Scaioli E, Barbaro MR, Biagi E, Laghi L, Cremon C, et al: Gut microbiota, metabolome and immune signatures in patients with uncomplicated diverticular disease. Gut 2017;66:1252-1261.

29 Spiller RC: Changing views on diverticular disease: impact of aging, obesity, diet, and microbiota. Neurogastroenterol Motil 2015;27: 305-312.

30 Bailey MB, Davenport DL, Procter L, McKenzie S, Vargas HD: Morbid obesity and diverticulitis: results from the ACS NSQIP dataset. J Am Coll Surg 2013;217:874-80.e1

31 Batra A, Siegmund B: The role of visceral fat. Dig Dis 2012;30:70-74.

32 Bargellini T, Martellucci J, Tonelli P, Valeri A: Long-term results of treatment of acute diverticulitis: still lessons to be learned? Updates Surg 2013;65:125-130.

33 Scarpa M, Pagano D, Ruffolo C, Pozza, Polese L, Frego M, et al: Health-related quality of life after colonic resection for diverticular disease: long-term results. J Gastrointest Surg 2009; 13:105-112.

34 Painter NS, Burkitt DP: Diverticular disease of the colon: a deficiency disease of western civilization. Br Med J 1971;2:450-454.

35 Milner P, Crowe R, Kamm MA, LennardJones JE, Burnstock G: Vasoactive intestinal polypeptide levels in sigmoid colon in idio- pathic constipation and diverticular disease. Gastroenterology 1990;99:666-675.

36 Peery AF, Barrett PR, Park D, Rogers AJ, Galanko JA, Martin CF, et al: A high-fiber diet does not protect against asymptomatic diverticulosis. Gastroenterology 2012;142:266272

37 Yamada E, Inamori M, Watanabe S, Sato T, Tagri M, Uchida E, et al: Constipation is not associated with colonic diverticula: a multicenter study in Japan. Neurogastroenterol Motil 2015;27:333-338.

38 Braunschmid T, Stift A, Mittlböck M, Lord A, Weiser FA, Riss S: Constipation is not associated with diverticular disease - analysis of 976 patients. Int J Surg 2015;19:42-45.

39 Agachan F, Chen T, Pfeifer J, Reissman P, Wexner SD: A constipation scoring system to simplify evaluation and management of constipated patients. Dis Colon Rectum 1996;39: 681-685.

40 Böttner M, Barrenschee M, Hellwig I, Harde J, Egberts JH, Becker T, et al: The GDNF System is altered in diverticular disease - implications for pathogenesis. PLoS One 2013; 8:e66290.

41 Bassotti G, Battaglia E, Bellone G, Dughera L, Fisogni S, Zambelli C, et al: Interstitial cells of Cajal, enteric nerves, and glial cells in colonic diverticular disease. J Clin Pathol 2005;58: 973-977.

42 Golder M, Burleigh DE, Belai A, Ghali L, Ashby D, Lunniss PJ, et al: Smooth muscle cholinergic denervation hypersensitivity in diverticular disease. Lancet 2003;361:1945-1951.

43 Simpson J, Sundler F, Humes DJ, Jenkins D, Scholefield JH, Spiller RC: Post inflammatory damage to the enteric nervous system in diverticular disease and its relationship to symptoms. Neurogastroenterol Motil 2009; 21:847-e5

44 Bercík P, Wang L, Verdú EF, Mao YK, Blennerhassett $\mathrm{P}$, Khan WI, et al: Visceral hyperalgesia and intestinal dysmotility in a mouse model of postinfective gut dysfunction. Gastroenterology 2004;127:179-187.

45 Galligan JJ, Patel BA, Schneider SP, Wang H, Zhao H, Novotny M, et al: Visceral hypersensitivity in female but not in male serotonin transporter knockout rats. Neurogastroenterol Motil 2013;25:e373-e381.

46 Simpson J, Sundler F, Humes DJ, Jenkins D, Wakelin D, Scholefield JH, et al: Prolonged elevation of galanin and tachykinin expression in mucosal and myenteric enteric nerves in trinitrobenzene sulphonic acid colitis. Neurogastroenterol Motil 2008;20: 392-406.

47 Simpson J, Neal KR, Scholefield JH, Spiller RC: Patterns of pain in diverticular disease and the influence of acute diverticulitis. Eur J Gastroenterol Hepatol 2003;15:10051010.

48 Clemens CH, Samsom M, Roelofs J, van Berge Henegouwen GP, Smout AJ: Colorectal visceral perception in diverticular disease. Gut 2004;53:717-722. 